\title{
New structural features of Acacia tortuosa gum exudate
}

\author{
Maritza Martínez ${ }^{a}$, Olga Beltrán ${ }^{a}$, Fernando Rincón ${ }^{\mathrm{a}, *}$, Gladys León de Pinto ${ }^{a}$, José Manuel Igartuburu ${ }^{\mathrm{b}}$ \\ ${ }^{a}$ Centro de Investigaciones en Química de los Productos Naturales, Facultad de Humanidades y Educación, Universidad del Zulia, P.O. BOX 526, Maracaibo, Venezuela \\ ${ }^{\mathrm{b}}$ Departamento de Química Orgánica, Facultad de Ciencias, Universidad de Cádiz, Puerto Real, Cádiz, Spain
}

\section{A R T I C L E I N F O}

\section{Article history:}

Received 20 October 2014

Received in revised form 29 January 2015

Accepted 24 February 2015

Available online 4 March 2015

\section{Keywords:}

Acacia tortuosa

Gum exudate

NMR spectroscopy

Proteic fraction

Galactosylation

\begin{abstract}
A B S T R A C T
Acacia tortuosa produces a clear gum, very soluble in water. Previous reports showed that it was constituted by four fractions, one of them an arabinogalactan-protein complex. The elucidation of the $A$. tortuosa gum structure by the combination of classical chemical methods, size exclusion chromatography and NMR spectroscopy, was the objective of this investigation. The data obtained show that the heteropolysaccharide is an arabinogalactan type II, highly ramified, with lateral chains at C-2 as well as at C-6 of the galactose 3-O residues; mono-O-substituted galactoses were not detected. There are residues of mannose, the arabinose, pyranose predominantly, is terminal and 2-O-linked. The abundance of the 4-O-methyl- $\alpha$-D-glucuronic acid was not previously reported. The proteic fraction is probably represented by an arabinogalactan-protein complex that binds poorly with $\beta$-glucosyl Yariv reagent, and two glycoproteins. The NMR spectra suggest that the carbohydrate links to hydroxyproline through the galactose (galactosylation).
\end{abstract}

두 2015 Elsevier Ltd. All rights reserved.

\section{Introduction}

Polysaccharides possess interesting applications as hydrocolloids, mainly due to their ability to (a) retain water, (b) increase the viscosity of aqueous dispersions, (c) form viscoelastic materials and (d) provide a suitable texture for specific commercial products. For this reason, they are widely used as moisture-control products, thickeners, gelling agents, stabilizers of different kinds of dispersion, crystallization inhibitors and even as emulsifiers (Braun \& Rosen, 2010; Imeson, 2010; Phillips \& Williams, 2009).

Only a few plant species are cultivated, at present, to obtain gums used in the food industry as additives: Acacia senegal, source of arabic gum; Astragalus spp., source of tragacanth; Cyamopsis tetragonolobus, source guar gum; Ceratonia siliqua, source of locust bean gum.

Acacia tortuosa (Leguminosae), a tropical American specie, located in Venezuela, produces a clear gum, very soluble in water (León de Pinto, Martínez, De Bolaño, Rivas, \& Ocando, 1998; León de Pinto, Martínez, Ortega, Villavicencio, \& Rojas, 1993). Previous

\footnotetext{
* Corresponding author at: Centro de Investigaciones en Química de los Productos Naturales, Facultad de Humanidades y Educación, Universidad del Zulia, Ciudad Universitaria, Av. Goajira, P.O. BOX 526, Maracaibo, Venezuela. Tel.: +58 261 8959169.

E-mail addresses: mmartinez.luz@gmail.com (M. Martínez), olga.beltran@hdes. luz.edu.ve (O. Beltrán), frinconciqpn@gmail.com (F. Rincón), gladysleondepinto@ yahoo.es (G. León de Pinto), josemanuel.igartuburu@uca.es (J.M. Igartuburu).
}

studies demonstrated that the gum contains mainly a polysaccharide and a proteinaceous material (Beltrán, León de Pinto, Martínez, \& Rincón, 2005). The polysaccharide contains galactose (69\%), arabinose (13\%), xylose $(<1 \%)$ and uronic acid $(18 \%)$. The nitrogen content is relatively high (6\%), in comparison with those reported for $A$. senegal (0.29\%) gum and for other Acacia gummiferae gums, such as, Acacia seyal (0.14\%), Acacia gerrardii (1.8\%), Acacia robusta (2.8\%) and Acacia tortilis (1.9\%) (Beltrán, León de Pinto, Martínez, \& Rincón, 2005; Islam, Phillips, Sliivo, Snowden, \& Williams, 1997; Sidigg, Osman, Al-Assaf, Phillips, \& Williams, 2005). The amino acid composition showed high proportions of hydroxyproline, serine, lysine and glycine; threonine glutamine, proline, alanine, valine, isoleucine, tyrosine, phenylalanine and histidine are also found as minor constituents, similar to those reported for A. seyal, A. gerrardii, A. robusta and A. tortilis (Beltrán, León de Pinto, Martínez, \& Rincón, 2005). Size exclusion chromatography, with multiangle laser light scattering data demonstrated that $A$. tortuosa gum is a highly polydisperse system (Beltrán, León de Pinto, Martínez, Picton, et al., 2005). The weight average molar mass $\left(\mathrm{Mw}=410,000 \mathrm{~g} \mathrm{~mol}^{-1}\right)$ and the number average molar mass $\left(\mathrm{Mn}=170,000 \mathrm{~g} \mathrm{~mol}^{-1}\right)$ are within the typical ranges reported for many Acacias (Al-Assaf, Phillips, \& Williams, 2005).

A. tortuosa gum aqueous dispersions (15-40\% w/v) displayed shear-thinning non-Newtonian flow properties at $20^{\circ} \mathrm{C}$, fitting the Sisko model, since a tendency towards a high-shear limiting Newtonian viscosity was observed. The aqueous dispersion gum of $A$. tortuosa ( $40 \% \mathrm{w} / \mathrm{v}$ ) exhibited clear viscoelastic properties from 
5 to $25^{\circ} \mathrm{C}$ (Muñoz et al., 2007). The surface tension of $A$. tortuosa $\operatorname{gum}(42.6 \mathrm{mN} / \mathrm{m})$, at a given concentration $(0.5 \% \mathrm{w} / \mathrm{v})$ (Muñoz et al., 2007), is below the value reported for gum arabic $(46.9 \mathrm{mN} / \mathrm{m}$ ) at the same concentration (Huang, Kakuda, \& Cui, 2001); the emulsifying properties of this last gum (Ibanoglu, 2002; Tan, 2004) have been related to a an arabinogalactan-protein complex (Picton, Bataille, \& Muller, 2000). The fractionation and characterization of $A$. tortuosa gum suggested the presence of an arabinogalactan (AG) and an arabinogalactan-protein complex (AGP) (Beltrán, León de Pinto, Martínez, Picton, et al., 2005).

Structural studies, by sugar composition, methylation analysis and 1D-NMR spectroscopy, suggested that the backbone of the polysaccharide structure is mainly a $\beta-\mathrm{D}(1 \rightarrow 3)$ galactan (León de Pinto et al., 1998). This nucleus also contains arabinose and uronic acid residues; the presence of these residues, vulnerable to periodate oxidation, requires a further study (León de Pinto et al., 1998).

This work reports new structural features of $A$. tortuosa gum exudate by the combination of classical chemical methods, size exclusion chromatography and 1D- and 2D-NMR spectroscopy.

\section{Materials and methods}

\subsection{Origin and purification of gum samples}

Gum from A. tortuosa (L) Wild (uveda), was collected in Zulia State (East of Maracaibo lake), Venezuela, South America, by the authors in January-March, 2012. The identification of voucher specimens was confirmed by Dr. Lourdes Cárdenas de Guevara, a botanical taxonomist of the Universidad Central de Venezuela. The gum exudate was purified as described previously (León de Pinto et al., 1998).

\subsection{General methods}

Neutral sugar compositions were determined by HPLC, with an IR detector (Waters $410,35^{\circ} \mathrm{C}$ ) and a carbohydrate column (Waters, WAT 044355 , oven $35^{\circ} \mathrm{C}$ ), an Acetonitrile:water (80:20) mixture was used as eluent (flow $1 \mathrm{ml} / \mathrm{min}$ ). The amino acid content was determined with a post-column derivatizer (Pickering laboratories) adapted to a Perkin Elmer 785 UV-visible detector $(570 \mathrm{~nm})$, a sodium cation exchange column (Pickering Laboratories) and buffer solutions ( $\mathrm{pH}: 3.8$ and 7.14) as eluent $(0.5 \mathrm{ml} / \mathrm{min})$ were used. The uronic acids values were determined by the Blumenkrantz-Asboe-Hansen method (Blumenkrantz \& Asboe-Hansen, 1973). The total protein and carbohydrate contents were evaluated, using the Lowry and phenol-sulfuric methods respectively (Dubois, Geilles, Hamilton, Reberts, \& Smith, 1956; Lowry, Rosenbough, Farr, \& Randall, 1951).

\subsection{Classical methods}

\subsubsection{Preparation of the degraded gums $A$ and $B$}

Purified gum (7.2 g) was hydrolyzed with sulfuric acid ( $5 \mathrm{mM}$, $\left.290 \mathrm{ml}, 96 \mathrm{~h}, 100^{\circ} \mathrm{C}\right)$. After cooling, neutralization and filtration, the solution was dialyzed against running tap water $(48 \mathrm{~h})$, using a Spectra/Por molecular membrane tubing (MWCO 12-14,000). The degraded gum A was obtained by freeze-drying. This hydrolysis gives information about the structure of the lateral chains.

Degraded gum B was prepared by a drastic Smith-degradation of degraded gum A. Degraded gum A ( $1.5 \mathrm{~g})$ was subjected to oxidation ( $\left.50 \mathrm{ml}, 0.25 \mathrm{M}, \mathrm{NaIO}_{4}\right)$, reduction $\left(0.5 \mathrm{~g}, \mathrm{NaBH}_{4}\right)$ and then acid hydrolysis $\left(0.5 \mathrm{M}, \mathrm{H}_{2} \mathrm{SO}_{4}\right)$ at room temperature for 2 days. The product was obtained by freeze-drying, after dialysis against tap water $(48 \mathrm{~h})$. This drastic degradation is used to obtain information about the nucleus of the studied polymer.

\subsubsection{Methylation analysis of the original gum}

The original gum was permethylated by two successive methylation processes (Haworth, 1915; Purdie \& Irvine, 1903). The corresponding alditol acetates were prepared from the permethylated polysaccharide, as described previously (León de Pinto et al., 2000). The alditol acetates were analyzed by GC-MS in a Hewlett Packard HP6890 GC coupled with a Hewlett Packard 5973A Mass-selective detector. The gas chromatograph was equipped with a capillary HP-5MS column $(30 \mathrm{~m} \times 0.25 \mathrm{~mm}$ i.d $0.25 \mathrm{~mm}$ ). The carrier gas was Helium $(1 \mathrm{ml} / \mathrm{min})$. The oven temperature was raised from 70 to $260^{\circ} \mathrm{C}$ at a rate of $6{ }^{\circ} \mathrm{C} / \mathrm{min}$ and then to $280^{\circ} \mathrm{C}$ at a rate of $25^{\circ} \mathrm{C}$ and held for $2 \mathrm{~min}$.

\subsection{NMR spectral studies of the degraded gums A and B}

Experiments were recorded in a Bruker Avance DRX-400 NMR spectrometer operated at 500.13 and $125.77 \mathrm{MHz}$, for ${ }^{1} \mathrm{H}$ and ${ }^{13} \mathrm{C}$ NMR, respectively. Studies included correlation spectroscopy (COSY), heteronuclear multiple quantum correlation (HMQC) and heteronuclear multiple bond correlation (HMBC). The degraded products (50-100 mg) were dissolved in deuterium oxide (0.5$1.0 \mathrm{ml}$ ); the analyses were performed at probe temperature $\left(27^{\circ} \mathrm{C}\right)$. NMR data were reported in ppm $(\delta)$ down field from $\mathrm{Me}_{4} \mathrm{Si}$; 1,4-dioxane was used as internal standard.

\subsection{Size exclusion chromatography of the original gum}

Size exclusion chromatography (SEC) was used in order to obtain the different molecular weight fractions of the original gum, this technique was performed in an open column, packed with Sephacryl S-500 HR (Sigma), and sodium chloride solution $(0.5 \mathrm{M})$ was used as a carrier $(0.5 \mathrm{ml} / \mathrm{min})$. The protein, at $280 \mathrm{~nm}$, and carbohydrate (by sulfuric acid method, at $490 \mathrm{~nm}$ ) contents were monitored with an UV-visible spectrometer. The elution profile was obtained plotting absorbance vs elution volume (León de Pinto, Sanabria, Martínez, Beltran, \& Igartuburu, 2002).

\subsection{Yariv reaction of the original gum}

Aliquots ( 4 and $40 \mu \mathrm{g}$ ) of the original gum, were subjected to rocket electrophoresis in agarose gels $(1 \% \mathrm{w} / \mathrm{w})$ containing $\beta$-glucosyl Yariv reagent, which selectively precipitates and stains AGPs as they move through the gel. Gum arabic was used as standard (Komalavilas, Zhu, \& Nothnagel, 1991).

Table 1

Sugar composition of Acacia tortuosa original gum and its fractions.

\begin{tabular}{lccrr}
\hline \multicolumn{5}{l}{ Proportion $(\% \mathrm{~m} / \mathrm{m})$} \\
\cline { 2 - 5 } Sample & $\mathrm{OG}^{\mathrm{a}}$ & $\mathrm{F} 1^{\mathrm{b}}$ & $\mathrm{F}^{\mathrm{c}}$ & $\mathrm{F}^{\mathrm{d}}$ \\
\hline Gugar & & & & \\
\hline Arabinose & $53 \pm 1.5$ & $32 \pm 0.6$ & $48 \pm 0.3$ & $52 \pm 0.7$ \\
Xylose & $28 \pm 1.5$ & $38 \pm 0.2$ & $39 \pm 0.6$ & $32 \pm 0.8$ \\
Mannose & $2 \pm 0.26$ & $6 \pm 0.2$ & $2 \pm 0.2$ & $3 \pm 0.5$ \\
Uronic acid & $7 \pm 0.5$ & $13 \pm 0.2$ & $5 \pm 0.3$ & $5 \pm 0.3$ \\
Total & $10 \pm 0.26$ & $11 \pm 0.3$ & $6 \pm 0.2$ & $8 \pm 0.4$ \\
\hline
\end{tabular}

a OG: Original gum.

b F1: Fraction one.

c F2: Fraction two.

d F3: Fraction three. 


\section{Results and discussion}

\subsection{Sugar composition of the original gum}

Sugar composition of $A$. tortuosa gum showed galactose (53\%), arabinose (28\%), xylose (2\%), mannose (7\%), and uronic acid $(10 \%)$ (Table 1). This composition of sugars differs from that reported before (León de Pinto et al., 1998) because it was difficult to separate galactose and mannose under the conditions employed using paper chromatography. The use of HPLC improved the resolution.

\subsection{Methylation analysis of the original gum}

Methylation analysis of $A$. tortuosa gum exudate (Table 2) showed the presence of 3-O, 2,3-di-O and 3,6-di-O- substituted galactose and terminal and 2-O-arabinose, as furanose and pyranose residues. These results suggest that the structure is a branched one with points of ramification on C-2 and/or C- 6 of the 3-O- $\beta$-D-galactose residues. Nevertheless, the methylation data differ from those published previously (León de Pinto et al., 1998), which suggested the presence of a less ramified structure with ramification points at $\mathrm{C}-6$ of the 3-O-galactose residues. In addition, they did not detect 2-O-linked arabinose. The complexity of the chromatographic profile of the methylglycosides used in the previous work made their identification difficult, in contrast to the greater simplicity and precision obtained for the alditol acetates (Churms, 1990).

\subsection{NMR spectroscopy of the degraded gums $A$ and $B$}

Application of 1D- and 2D-NMR spectroscopy to the degraded products, obtained from the original gum, led to complete previous reports (León de Pinto et al., 1998). Signal assignments were based on chemical evidence and comparisons with model compounds (Agrawal, 1992; Bock \& Pedersen., 1983; Brewer, Hunter, \& Lajoie, 1998; Martínez et al., 2003; Scott, Faulker, Rubins, \& Buschman, 2000).

Degraded gum A, was constituted by galactose (70\%), arabinose (9\%) and uronic acids (21\%). The COSY spectrum showed the spin systems $\mathrm{H}-1 / \mathrm{H}-2$ : 4.50/3.60; 4.50/3.45; 4.50/3.35; 4.50/3.20 (Fig. 1a). The anomeric proton (4.5 ppm) is directly linked to a carbon that resonates at $102.41 \mathrm{ppm}$ (Fig $1 \mathrm{~b}$ ). These NMR data suggested the existence of non-reducing 3-O- $\beta$-D-galactose residues, which are probably in four different chemical environments.

There were correlation signals 5.28/3.6, in the COSY spectrum (Fig. 1a) related to the presence of the resonances at 5.28/92.41 and 5.28/68 in HMQC and HMBC spectrum, respectively (Fig. 1b

Table 2

Methylation analyses of the original gum from Acacia tortuosa.

\begin{tabular}{|c|c|c|c|}
\hline O-Methyl sugars & $\operatorname{Tr}^{\mathrm{a}}$ & Type of linkage & Characteristic fragments $(\mathrm{m} / \mathrm{z})$ \\
\hline $2,3,5-\mathrm{Me}_{3}-\mathrm{Ara}^{\mathrm{b}}$ & 1.00 & $\operatorname{Araf}^{\mathrm{d}}(1 \rightarrow$ & $45,71,87,101,117,129,161$ \\
\hline 2,3,4-Me $-\mathrm{Ara}^{\mathrm{b}}$ & 1.04 & $\operatorname{Arap}^{e}(1 \rightarrow$ & $87,101,117,161$ \\
\hline 3,5-Me $2-\mathrm{Ara}^{\mathrm{b}}$ & 1.12 & $\rightarrow 2) \operatorname{Araf}^{\mathrm{d}}(1 \rightarrow$ & $45,71,87,101,129,161,189$ \\
\hline $3,4-\mathrm{Me}_{2}-\mathrm{Ara}^{\mathrm{b}}$ & 1.15 & $\rightarrow 2) \operatorname{Arap}^{\mathrm{e}}(1 \rightarrow$ & $87,101,117,129,189$ \\
\hline $2,3,4,6-\mathrm{Me}_{4}-\mathrm{Gal}^{\mathrm{C}}$ & 1.31 & Galp $^{\mathrm{f}}(1 \rightarrow$ & $\begin{array}{l}71,87,101,117,129,145,161, \\
205\end{array}$ \\
\hline $2,4,6-\mathrm{Me}_{3}-\mathrm{Gal}^{\mathrm{C}}$ & 1.32 & $\rightarrow 3) \operatorname{Galp}^{\mathrm{f}}(1 \rightarrow$ & $45,101,117,129,161,233$ \\
\hline $4,6-\mathrm{Me}_{2}-\mathrm{Gal}^{\mathrm{c}}$ & 1.38 & $\rightarrow 2,3) \operatorname{Galp}^{\mathrm{f}}(1 \rightarrow$ & $45,85,101,115,129,161,261$ \\
\hline $2,4-\mathrm{Me}_{2}-\mathrm{Gal}^{\mathrm{C}}$ & 1.46 & $\rightarrow 3,6)$ Galp $^{\mathrm{f}}(1 \rightarrow$ & $87,117,129,189,233$ \\
\hline
\end{tabular}

${ }^{\text {a }}$ Retention times relative to 1,4-di-O-acetyl-2,3,5-tri-O-methyl arabinitol (15.95 $\mathrm{min})$.

b Ara: Arabinose.

c Gal: Galactose.

d Araf: Arabinofuranose.

e Arap: Arabinopyranose.

${ }^{f}$ Galp: Galactopyranose.
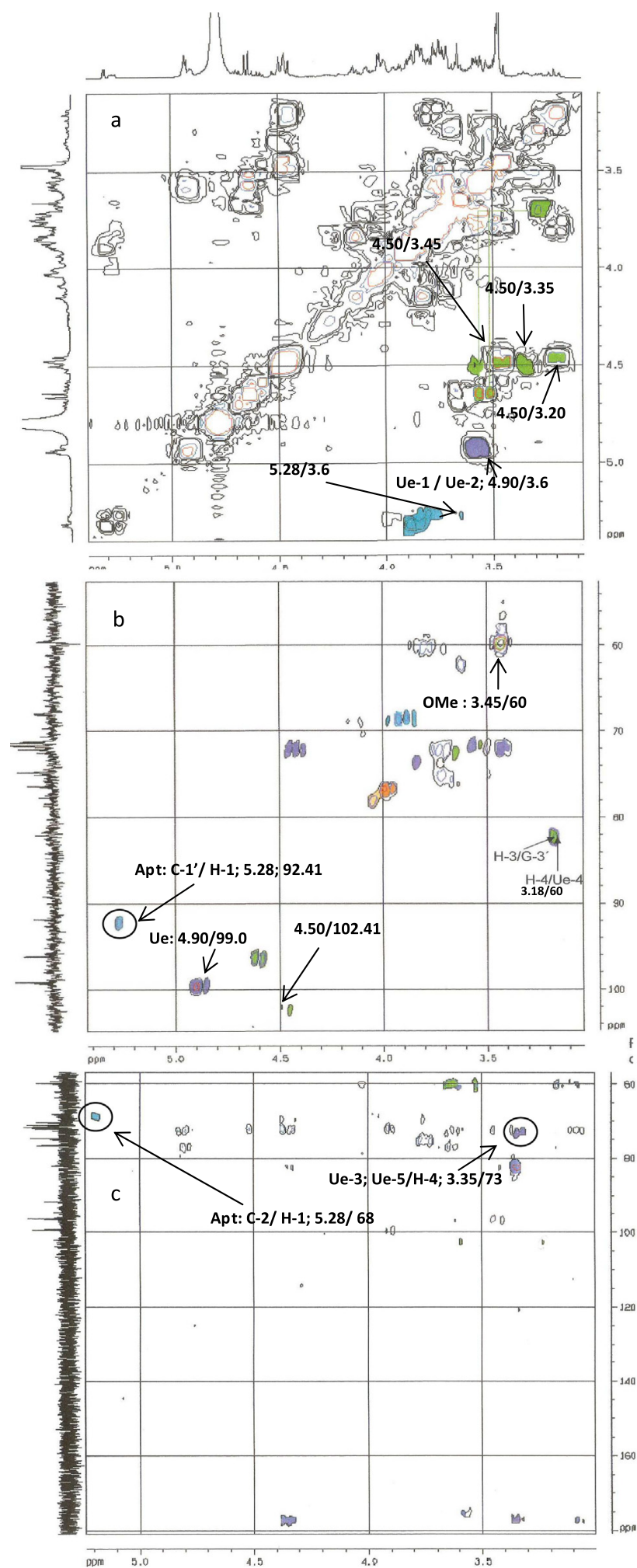

Fig. 1. NMR data for Acacia tortuosa degraded gum A. (a) COSY, (b) HMQC, (c) HMBC. Apt $=$ Terminal arabinopyranose. Ue $=4-0$-Methyl- $\alpha$-ether. OMe $=$ Methoxyl group.

and c). The signals at 5.28, 92.41 and $68 \mathrm{ppm}$ were assigned to $\mathrm{H}-1, \mathrm{C}-1$ and $\mathrm{C}-2$ of terminal $\beta$-L-arabinopyranose residues, respectively.

On the other hand, the COSY spectrum (Fig. 1a) showed that a resonance at $4.90 / 3.6$ correlated with that which appeared at 
4.90/99.0 ppm in HMQC spectrum (Fig. 1b). The signals at 4.90 and 99.0 ppm were assigned to $\mathrm{H}-1$ and $\mathrm{C}-1$ of $4-0$-methyl- $\alpha$-D-glucuronic acid. In addition, other resonances were observed assignable to this uronic acid, i.e., 3.45/60; 3.35/73 (Fig. 1b and c).

The methoxyl signal $(59.33 ; 60.00 \mathrm{ppm})$ did not invert in the DEPT 135 spectrum (data not shown). The NMR spectroscopy data demonstrated the abundance of 4-O-methyl- $\alpha$-D-glucuronic acid in the structure of the $A$. tortuosa gum which was not described in the previous work (León de Pinto et al., 1998).

Degraded gum B was constituted by galactose (60\%), arabinose (10\%) and uronic acids (30\%) and represents the backbone of the structure of the gum from $A$. tortuosa. The COSY spectrum (Fig. 2a) shows the spin correlations 4.46/3.47 and 4.40/3.47 ppm, due probably to $\mathrm{H}-1 / \mathrm{H}-2$ of 3-O- $\beta$-D-galactose residues in different environments. According to the HMQC spectrum (Fig. 2b) the $\mathrm{H}-2$ proton
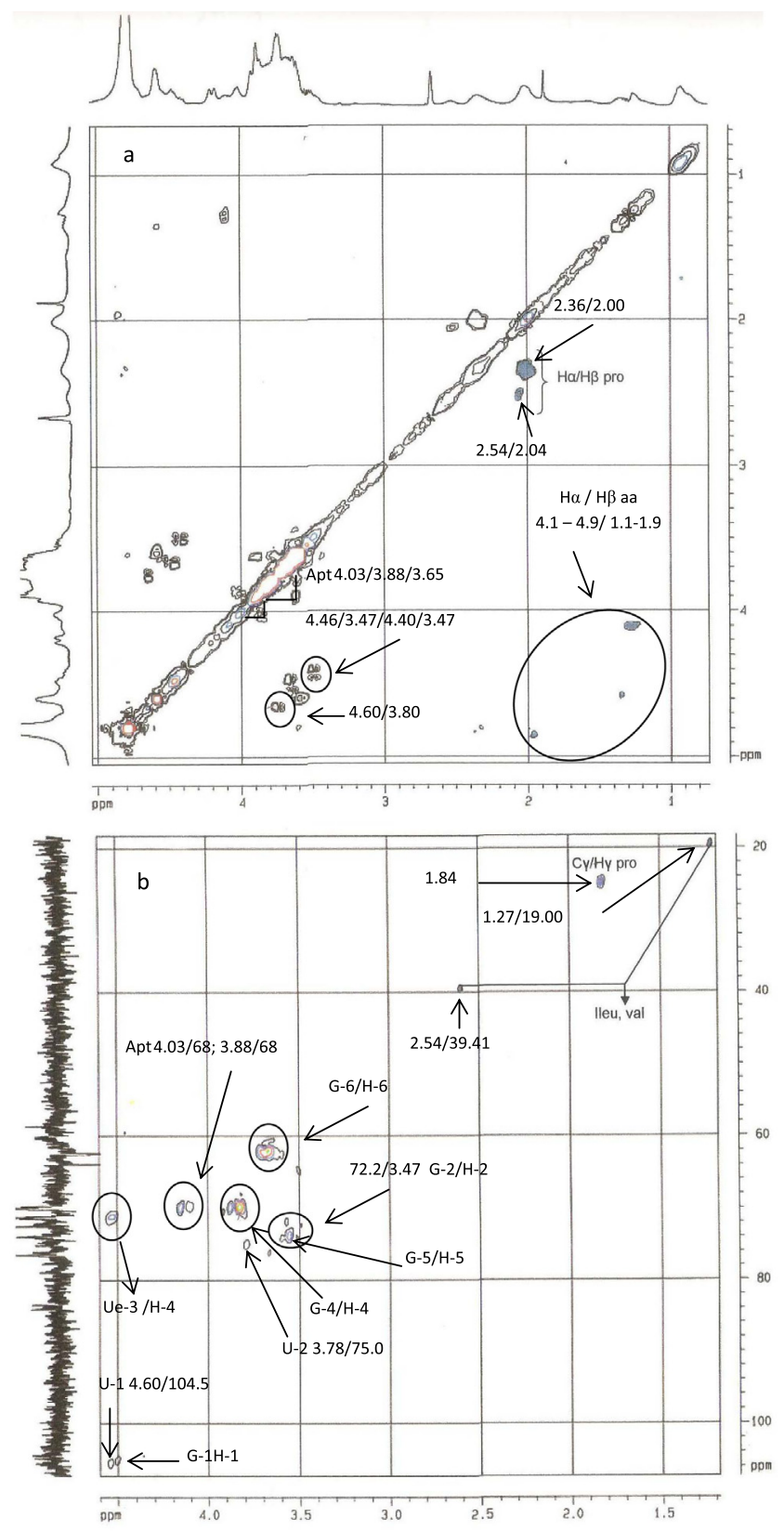

Fig. 2. NMR spectral data for Acacia tortuosa degraded gum B. (a) COSY, (b) HMQC. Apt $=$ Terminal arabinopyranose residues. Ue $=4-0$-Methyl- $\alpha$-D-glucuronic acid $\mathrm{G}=$ galactose residues, $\mathrm{H} \alpha / \mathrm{H} \beta=$ protons $\alpha$ and $\beta$ amino acids, Pro=proline, Leu = leucine, $\mathrm{Val}=$ valine, $\mathrm{C} \gamma / \mathrm{H} \gamma$ pro = proline carbon and proton $\gamma$.
(3.47 ppm) is directly linked to C-2 (72.25 ppm) as was expected. Spin correlations $\mathrm{G}-4 / \mathrm{H}-4, \mathrm{G}-5 / \mathrm{H}-5$ and $\mathrm{G}-6 / \mathrm{H}-6$ were also observed, as has been reported for other polysaccharide gums (León de Pinto et al., 2002; Martínez et al., 2003) (Fig. 2b).

There were observed correlations at 4.03/3.88/3.65 and 4.03/ $68 ; 3.88 / 68$, (Fig. 2a and b) respectively, probably due to terminal $\beta$-L-arabinopyranose, which was not detected in the previous work (León de Pinto et al., 1998). These residues may be removed by periodate oxidation, but steric hindrance and the formation of hydrogen linkage between some sugar residues may preclude its elimination, as has been described for other polysaccharides gums (Martínez, León de Pinto, Rivas, \& Ocando, 1996).

The COSY spectrum of degraded gum B exhibited the spin system protons $4.60 / 3.80$ (Fig. $2 \mathrm{a}$ ) due to $\beta$-D-glucuronic acid. The protons (4.60 and $3.78 \mathrm{ppm})$ are linked directly to $\mathrm{C}-1$ (104.5 ppm) and $\mathrm{C}-2(75.00 \mathrm{ppm})$, respectively, as has been shown by the HMQC spectrum (Fig. 2b).

The DEPT-135 (data not shown) showed an inverted signal (69.97 ppm), assignable to C-6 $\beta$-D-galactose, which may be linked to the uronic acids and/or the terminal $\beta$-L-arabinopyranose residues in the backbone of the structure, as a confirmation of the persistence of these residues in the nucleus.

\subsection{Isolation and characterization of the fractions from the original gum}

Fractionation by size-exclusion chromatography (open column) of the original gum, showed three main fractions that contain carbohydrate and protein (Table 3 ). Fraction 1 contains the highest carbohydrate content $(86 \% \mathrm{~m} / \mathrm{m})$, but lower protein proportion $(12 \% \mathrm{~m} / \mathrm{m})$ with a predominance of serine and hydroxyproline (Table 3), which suggests the presence of an AGP complex in A.tortuosa gum, as was described previously (Beltrán, León de Pinto, Martínez, Picton, et al., 2005). The carbohydrate composition of this fraction, showed a galactose:arabinose ratio of 32:38, which is still in the range reported for an AG type II (Table 1) (Fincher, Stone, \& Clarke, 1983; Gaspar, Johson, Mckenna, Bacic, \& Schultz, 2001).

On the other hand, fractions 2 and 3 present higher protein content, with low amounts of hydroxyproline, which suggests that they could be glycoproteins (Table 3).

Yariv reaction gave a diffuse halo for the original $A$. tortuosa gum (data not shown), distinct from the well defined halo produced by gum Arabic, which demonstrates that the studied gum binds poorly to $\beta$-glucosyl Yariv reagent; this behavior has been reported for $A$. seyal gum and cashew-nut tree exudate gum (Islam et al., 1997; Pereira et al., 2007). This result suggests that A. tortuosa gum could possess an AGP weakly stained by the $\beta$-glucosyl Yariv reagent.

\subsection{NMR spectroscopy of the proteic fractions from degraded gum $B$}

COSY and HMQC spectra from degraded gum B (Fig. 2a and b) gave interesting information about the proteic fraction present in

Table 3

Carbohydrate and protein contents of Acacia tortuosa original gum and its fractions.

\begin{tabular}{llll}
\hline Sample & Yield $(\% \mathrm{~m} / \mathrm{m})$ & Carbohydrate $(\% \mathrm{~m} / \mathrm{m})$ & Protein $(\% \mathrm{~m} / \mathrm{m})$ \\
\hline${ }^{\mathrm{a} O G}$ & & $51 \pm 0.5$ & $42 \pm 0.5$ \\
${ }^{\mathrm{b}} \mathrm{F} 1$ & 13 & $86 \pm 0.5$ & $12 \pm 0.3$ \\
${ }^{\mathrm{C}} \mathrm{F} 2$ & 46 & $42 \pm 0.7$ & $53 \pm 0.5$ \\
${ }^{\mathrm{d}} \mathrm{F} 3$ & 41 & $34 \pm 0.4$ & $63 \pm 0.3$ \\
\hline
\end{tabular}

a OG: Original gum.

b F1: Fraction one.

c F2: Fraction two.

d F3: Fraction three. 


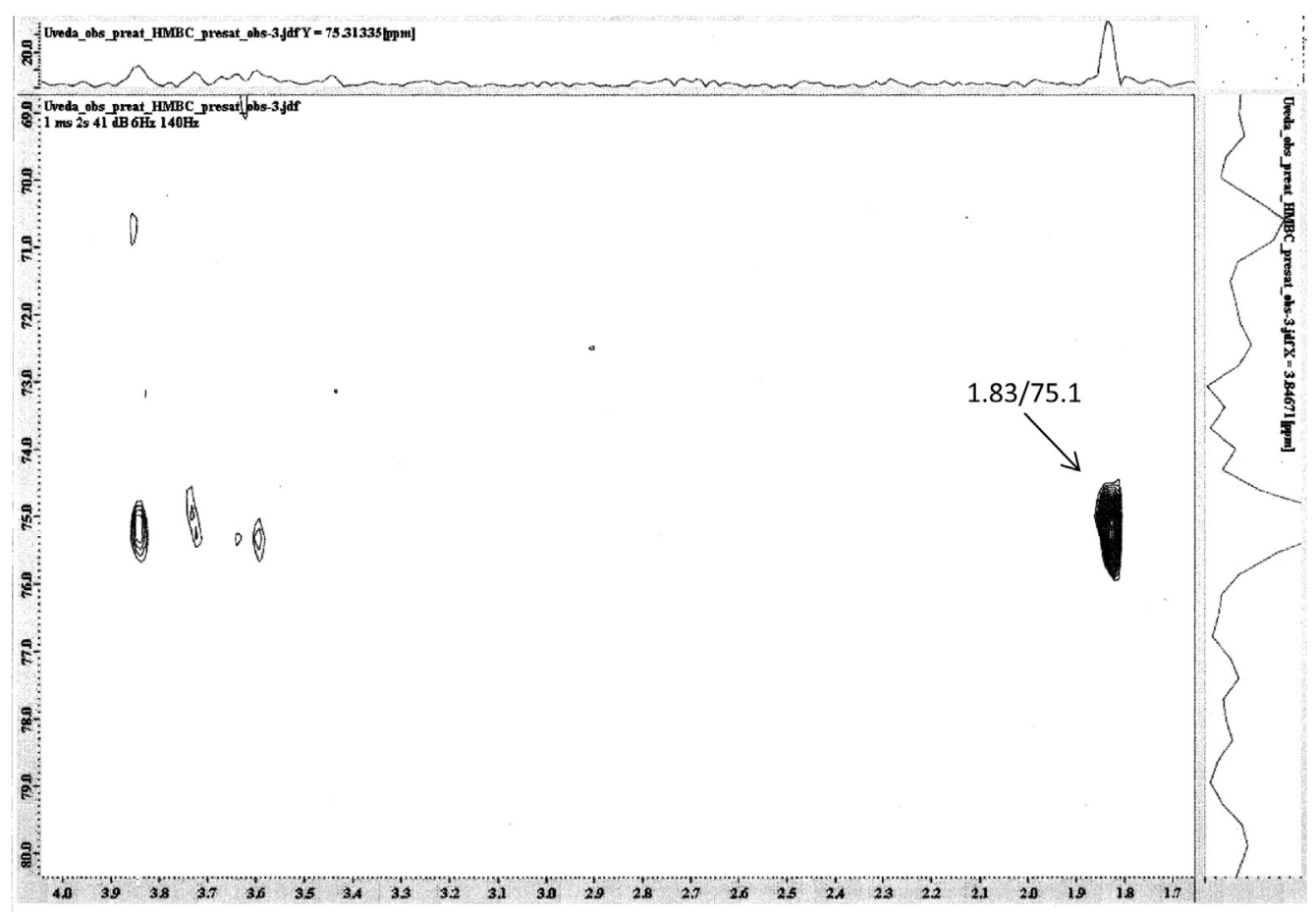

Fig. 3. HMBC spectrum from Acacia tortuosa degraded gum B.

the backbone structure of the $A$. tortuosa gum. The COSY spectrum (Fig. 2a) showed correlations, probably due to amino acids present in the nucleus. There were observed signals (4.1-4.9/1.1-1.9, Fig. 2a) which could be assigned to protons from $\alpha / \beta$ of amino acids (Brewer et al., 1998). The correlation 2.54/2.04; 2.36/2.00 ppm (Fig. 2a) may also correspond to $\mathrm{H} \beta / \mathrm{H} \sigma$ of proline (Scott et al., 2000). In addition, the HMQC spectrum of degraded gum $B$ (Fig. $2 \mathrm{~b}$ ) revealed that the protons at 2.54 and $1.27 \mathrm{ppm}$ are linked to the carbons (39.41 and $19.00 \mathrm{ppm}$ ) assignable to $C \beta$ and the $\mathrm{CH}_{3}$ group of aliphatic amino acids, such as leucine and valine, respectively, while protons at $1.84 \mathrm{ppm}$ are probably linked to a C- $\gamma$ of proline (Scott et al., 2000).

The HMBC spectrum of degraded gum B (Fig. 3) showed a main correlation signal at high field, $1.83 / 75.10 \mathrm{ppm}$ which may suggest the presence of a covalent linkage between galactose and hydroxyproline residues. The signal at 75.1, assignable to $\mathrm{C}-\gamma$ of hydroxyproline, was shifted to low field due the galactosylation, and was scalar-correlated, through three linkages, with $\mathrm{H}-\alpha$ (Tan et al., 2010). The presence of this linkage between the protein and carbohydrate, in A. tortuosa gum, was not reported previously (León de Pinto et al., 1998).

\section{Conclusions}

The heteropolysaccharide of the A. tortuosa gum is an AG type II, highly ramified, with lateral chains at $C-2$ as well as at C- 6 of the galactose 3-O residues; mono-O-substituted galactoses were not detected. There are residues of mannose; the arabinose (pyranose predominantly) is terminal and 2-O-linked.

The abundance of the 4-O-methyl- $\alpha$-D-glucuronic acid in its structure was not previously reported.

The proteic fraction is probably represented by an AGP complex, that binds poorly with $\beta$-glucosyl Yariv reagent, and two glycoproteins, isolated and characterized according to their composition. There were some amino acid signals, well distinguished from the carbohydrate in the NMR spectra. In the same way, the NMR data suggested that the carbohydrate links to the hydroxyproline through the galactose (galactosylation).

\section{Acknowledgments}

The authors acknowledge to Universidad del Zulia - Venezuela (CONDES and International Relations Department) and Universidad de Cadiz, Spain for their kind support.

\section{Appendix A. Supplementary data}

Supplementary data associated with this article can be found, in the online version, at http://dx.doi.org/10.1016/j.foodchem.2015. 02.124 .

\section{References}

Agrawal, P. K. (1992). NMR-spectroscopy in the structural elucidation of oligosaccharides and glycosides. Phytochemistry, 3, 3307-3329.

Al-Assaf, S., Phillips, G., \& Williams, P. (2005). Studies on Acacia exudate gums: Part II. Molecular weight comparison of the Vulgares and Gummiferae series of Acacia gums. Food Hydrocolloids, 19, 661-667.

Beltran, O., León de Pinto, G., Martínez, M., Picton, L., Cozic, C., Le Cerf, D., et al. (2005). Fractionation and characterization of gum from Acacia tortuosa. Effect of enzymatic and alkaline treatment. Carbohydrate Polymers, 62, 239-244.

Beltrán, O., León de Pinto, G., Martínez, M., \& Rincón, F (2005). Comparación de los datos analíticos de las gomas de Acacia macracantha, Acacia tortuosa y otras Gummiferae. Afinidad, 62(517), 237-241.

Blumenkrantz, N., \& Asboe-Hansen, G. (1973). Method for quantitative determination of uronic acid. Analytical Biochemistry, 54, 484-489.

Bock, K., \& Pedersen (1983). Carbon-13 nuclear magnetic resonance spectroscopy of monosaccharides. Advances in Biochemistry, 41, 27-63.

Braun, D. B., \& Rosen, M. R. (2010). Rheology modifiers handbook. Practical use and applications. New York: William Andrew Publishing (pp. 509).

Brewer, D., Hunter, H., \& Lajoie, G. (1998). NMR studies of the antimicrobial salivary peptides histatin 3 and histatin 5 in aqueous and non-aqueous solution. Biochemical Cellular Biology, 76, 247-256.

Churms, S. (1990). Recent developments in the chromatography analysis of carbohydrate. Journal of Chromatography, 500, 555-583.

Dubois, M., Geilles, K., Hamilton, A., Reberts, P., \& Smith, F. (1956). Colorimetric method for determination of sugars and related substances. Analytical Chemistry, 28, 350-355. 
Fincher, G., Stone, B., \& Clarke, A. (1983). Arabinogalactan-proteins: Structure, biosynthesis and function. Plant Physiology, 34, 47-70.

Gaspar, Y., Johson, Kim., Mckenna, J., Bacic, A., \& Schultz, C. (2001). The complex structures of arabinogalactan-proteins and the journey towards understanding function. Plant Molecular Biology, 47, 161-176.

Haworth, W. N. (1915). A new method of preparing alkylated sugars. Journal of the Chemical Society, 107, 8-16.

Huang, X., Kakuda, Y., \& Cui, W. (2001). Hydrocolloids in emulsions: Particle size distribution and interfacial activity. Food Hydrocolloids, 15, 533-542.

Ibanoglu, E. (2002). Rheological behaviour of whey protein stabilized emulsions in the presence of gum arabic. Journal of Food Engineering, 52, 272-277.

Imeson, A. (2010). Food stabilisers, thickeners and gelling agents. Chichester: WileyBlackwell.

Islam, A., Phillips, G., Sliivo, A., Snowden, M., \& Williams, P. A. (1997). A review of recent developments on the regulatory structural and functional aspects of gum arabic. Food Hydrocolloids, 11(4), 493-505.

Komalavilas, P., Zhu, J., \& Nothnagel, E. A. (1991). Arabinogalactan-proteins from the suspension culture medium and plasma membrane of rose cells. The Journal of Biological Chemistry, 266, 15956-15965.

León de Pinto, G., Martínez, M., Beltrán, O., Rincón, F., Igartuburu, J., \& Rodriguez, F. (2000). Structural investigation of the polysaccharide of Spondias mombin gum. Carbohydrate Polymers, 43, 105-112.

León de Pinto, G., Martínez, M., De Bolaño, L., Rivas, C., \& Ocando, E. (1998). The polysaccharide gum from Acacia tortuosa. Phytochemistry, 47, 53-56.

León de Pinto, G., Martínez, M., Ortega, S., Villavicencio, N., \& Rojas, L. (1993). Comparison of gum specimens from Acacia tortuosa and other Gummiferae species. Biochemical Systematics and Ecology, 21, 795-797.

León de Pinto, G., Sanabria, L., Martínez, M., Beltran, O., \& Igartuburu, J. (2002). Structural elucidation of proteic fraction isolated from Acacia glomerosa gum. Food Hydrocolloids, 16, 599-603.

Lowry, O., Rosenbough, N., Farr, A., \& Randall, R. (1951). Protein measurement with the folin phenol reagent. The Journal of Biochemical Chemistry, 193, 265-275.
Martínez, M., León de Pinto, G., Rivas, C., \& Ocando, E. (1996). Chemical and spectroscopic studies of the gum polysaccharide from Acacia macracantha Carbohydrate Polymer, 29, 247-252.

Martínez, M., León de Pinto, G., Sanabria, L., Beltrán, O., Igartuburu, J., \& Bhasas, A (2003). Structural features of an arabinogalactan gum exudates from Spondias dulcis (Anacardiaceae). Carbohydrate Research, 338, 619-624.

Muñoz, J., Rincón, F., Alfaro, M. C., Zapata, I., de la Fuente, J., Beltrán, O., et al. (2007). Rheological properties and surface tension of Acacia tortuosa gum exudate aqueous dispersions. Carbohydrate Polymers, 70, 198-205.

Pereira, A., Pettolino, F., Araujo, C., Fogagnoli, F., Bacic, A., dos Anjos, A., et al. (2007) Cashew-nut tree exudate gum: Identification of an arabinogalactan-protein as a constituent of the gum and use on the stimulation of somatic embryogenesis. Plant Science, 173, 468-477.

Phillips, G. O., \& Williams, P. O. (2009). Handbook of hydrocolloids (2nd ed.) Cambridge: Woodhead Publishing.

Picton, L., Bataille, I., \& Muller, G. (2000). Analysis of a complex polysaccharide (gum arabic) by multi-angle laser light scattering coupled on-line to size exclusion chromatography and flow field flow fractionation. Carbohydrate Polymer, 42, 23-31.

Purdie, T. \& Irvine, J. C. (1903). The alkylation of sugars. Journal of the Chemical Society, 83, 102

Scott, S. M., Faulker, D., Rubins, K., \& Buschman, F. D. (2000). Dolastatin 3 and two novel cyclic peptides from palauan collection of Lyngbya majuscule. Journal of Natural Products, 63, 279-282.

Siddig, N. E., Osman, M. E., Al-Assaf, S., Phillips, G. O., \& Williams, P. A. (2005). Studies on Acacia exudates gums. Part IV. Distribution of molecular components in Acacia seyal in relation to Acacia senegal. Food Hydrocolloids, 19, 679-686.

Tan, C. T. (2004). Beverage emulsions. In S. Friberg, K. Larsson, \& J. Sjoblom (Eds.) Food emulsions (4th ed.. New York: Marcel Dekker.

Tan, L., Varnai, P., Lamport, D., Yuan, Ch., Xu, J., Qiu, F., et al. (2010). Plant Ohydroxyproline arabinogalactans are composed of repeating trigalactosyl subunits with short bifurcated side chains. The Journal of Biological Chemistry, $285,24575-24583$. 